DOI: https://doi.org/10.24867/09DS05Stijovic

\title{
ANALIZA LOGISTIČKIH PROCESA U KOMPANIJI ZA PROIZVODNJU AUTOMOBILSKIH KABLOVSKIH SNOPOVA
}

\section{ANALYSIS OF LOGISTICS PROCESSES IN A COMPANY FOR THE PRODUCTION OF AUTOMOTIVE CABLE BUNDLES}

\author{
Vladimir Stijović, Fakultet tehničkih nauka, Novi Sad
}

\section{Oblast - SAOBRAĆAJ}

Kratak sadržaj - U radu je izvršena analiza logističkih procesa unutar kompanije za proizvodnju kablovskih snopova, prvo sa aspekta mapiranja logističkih procesa a nakon toga njihove analize uz pomoć odgovarajucih modela razvijenih $u$ excelu.

Ključne reči: Logistički procesi, analiza, automobilski industrija, dijagram toka procesa, excel, model.

Abstract - The aim of this paper can be defined as reviewing and analyzing of logistics processes within case study company through processes mapping, with the final aim of describing and analyzing activities and tasks performed by the company's logistics sector.

Keywords: Logistics processes, analysis, automotive industry, workflow diagram, excel, model.

\section{UVOD}

Automobilska industrija spada $\mathrm{u}$ jednu od najsloženijih industrija danas, što prouzrokuje složen lanac snabdevanja. Ovako složenim sistemima neophodno je upravljati na odgovarajući način da bi se zadovoljili osnovni ekonomski, a sve više ekološki i društveni principi. Proizvođači automobila, koji se u kontekstu poslovne logistike i upravljanja lancima snabdevanja označavaju kao OEM kompanije (engl. original equipment manufacturer), kao što su BMW, Audi i Mercedes, kompanije koje ne proizvode sve svoje delove i sisteme unutar svojih kompanija, već se određeni poluproizvodi, delovi, sistemi i uređaji proizvode $u$ drugim kompanijama, odakle se vrši isporuke ka OEM preduzećima. Dobavljači koji svoje gotove proizvode direktno isporučuju ka OEM proizvođačima predstavljaju tzv. dobavljače prvog reda ili nivoa u lancu snabdevanja (engl. Tier 1). Primer Tier 1 dobavljača je kompanija koja proizvodi kablovske snopove o kojoj će se detaljnije govoriti u nastavku rada.

Zadatak rada može se definisati kao sagledavanje i analiziranje logističkih procesa, kroz mapiranje procesa unutar kompanije za proizvodnju kablovskih snopova $\mathrm{i}$ definisanja određenog sistema podrške odlučivanju, sa ciljem da se opišu i analiziraju aktivnosti i zadaci koje obavlja sektor logistike kompanije, a sa krajnjim ciljem unapređenja logistike i poslovanja generalno.

\footnotetext{
NAPOMENA:

Ovaj rad proistekao je iz master rada čiji mentor je bio dr Marinko Maslarić, vanr. prof.
}

\section{TEORIJSKE OSNOVE}

\subsection{Logistika}

Logistika se razvila $\mathrm{u}$ priznatu oblast $\mathrm{u}$ poslednjih pedesetak godina prošlog veka. Promene na raznim poljima, poput tehničko-tehnološkog razvoja, organizacije poslovanja i prakse su uticale $i$ na promene unutar logističkih sistema. Ciljevi logistike moraju biti usklađeni sa ciljevima preduzeća sa jedne strane, i u skladu sa nacionalnim interesima i propisima sa druge strane. Glavni cilj jeste poboljšanje ukupnog kvaliteta i minimizacija ukupnih troškova [1].

Pojednostavljeni pregled logističkih aktivnosti koje se realizuju u proizvodnoj kompaniji, omogućavajući protok materijala i njegovu transformaciju do finalnih proizvoda, prikazan je na slici 1 . Međutim, u kompanijama se po pravilu ovim aktivnostima upravlja odvojeno ( $\mathrm{u}$ kompaniji mogu postojati organizacione jedinice za nabavku, proizvodnju, transport, skladištenje), što prouzrokuje prekide u protoku materijala, deli logistiku i stvara niz problema. Logistički pristup podrazumeva uspostavljanje jedinstvene logističke funkcije u kompaniji koja je nadležna za upravljanje svim aktivnostima vezanim za skladišenje i protok materijala.

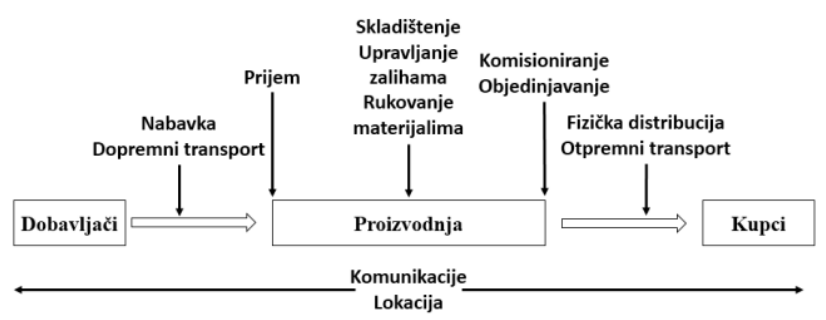

Slika 1. Pregled logističkih aktivnosti i procesa u kompaniji [1]

\subsection{Upravljanje lancima snabdevanja}

$\mathrm{Na}$ savremene koncepte u logistici i pravce njihovog razvoja u velikoj meri uticali su trendovi, kao što su globalizacija, autosorsing (engl. Outsourcing), slobodna trgovina, primena savremenih informacionih tehnologija, itd. Koncept, koji je u direktnoj vezi sa logističkim konceptom i za koga se najčešće navodi da predstavlja širenje integrisanog logističkog upravljanja sa nivoa jedne kompanije na nivo više kompanija, je upravljanje lancima snabdevanja (slika 2). Lanac snabdevanja je "mreža organizacija koje su povezane i koje se nalaze $u$ odgovarajućim odnosima u procesima i aktivnostima kojima se stvaraju vrednosti u obliku proizvoda i usluga sa aspekta krajnjeg korisnika" [1]. 


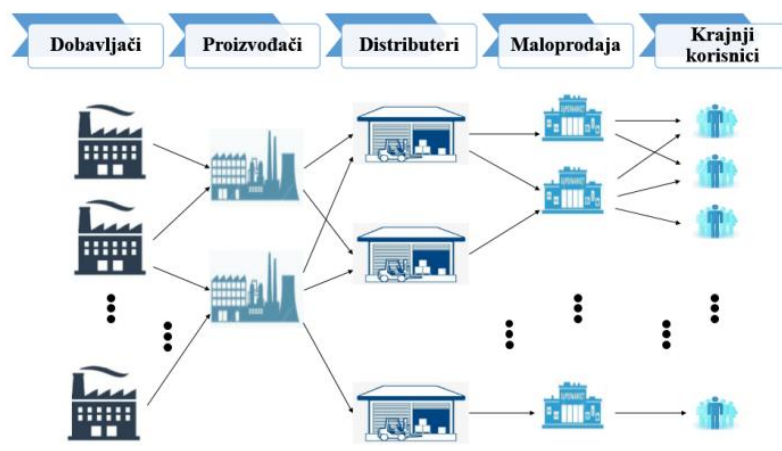

Slika 2. Šematski prikaz lanca snadbevanja unutar mreže lanca snabdevanja

\section{AUTOMOBILSKA INDUSTRIJA}

\subsection{Istorijat proizvodnje automobila}

Počeci automobilske industrije povezuju se sa nastankom vozila Ford Model T, gde je po prvi put do tada započeta serijska proizvodnja automobila. Prvi komercijalni primerak Modela T (slika 3) proizveden je 27. septembra 1908. godine u Detroitu. Zahvaljujući masovnoj proizvodnji, vozilo Ford Model $\mathrm{T}$ je postalo pristupačano i slojevima srednje klase u SAD [3].

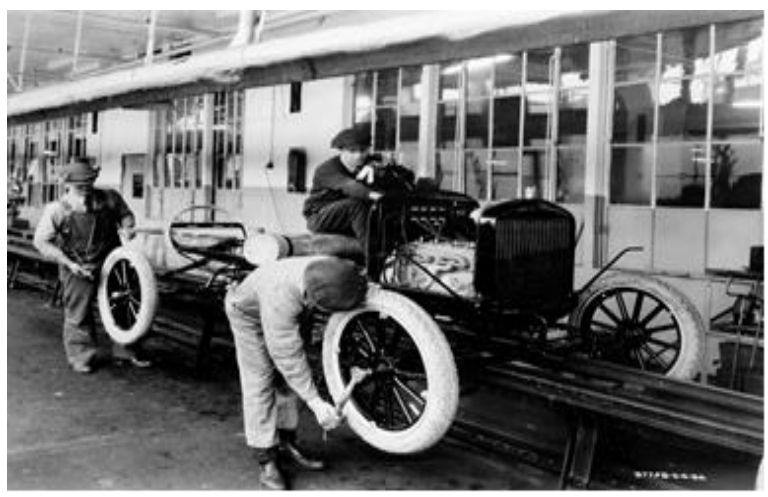

Slika 3. Počeci serijske proizvodnje Ford Model T [3]

U periodu do 1930. godine, $90 \%$ vozila je proizvedeno u Sjedinjenim Američkim Državama (SAD). Nakon Drugog svetskog rata SAD su i dalje najveći proizvođač automobila u svetu sa $75 \%$ ukupne proizvodnje. 1980. godine Japan je pretekao SAD po broju proizvedenih automobila, dok je 2018. godine Kina postala glavni proizvođač automobila u svetu [4].

\subsection{Automobilska industrija u Srbiji}

Automobilska industrija Srbije ima tradiciju dugu više od 80 godina koja datira od 1939. godine, kada Zastava, prvi srpski proizvođač motornih vozila počinje sa proizvodnjom automobila proizvedenih pod licencom Fiata. Automobilska industrija je danas jedna od najistaknutijih sektora u Srbiji, što čini gotovo 10\% ukupnog iznosa FDI (engl. Foreign direct investment) od 2001 godine. Oko 60 međunarodnih investitora uložili su više od 1,7 milijardi $€$ u automobilsku industriju, stvarajući više od 27.000 radnih mesta [5].

\subsection{Osnove faze proizvodnje automobila}

Proces proizvodnje automobila se sastoji iz četiri pogona: preseraj, karoserija, lakirnica i montaže, pri čemu svaki automobil mora proći navedene pogone, kako bi se na kraju dobio gotov proizvod po narudžbenici kupca.

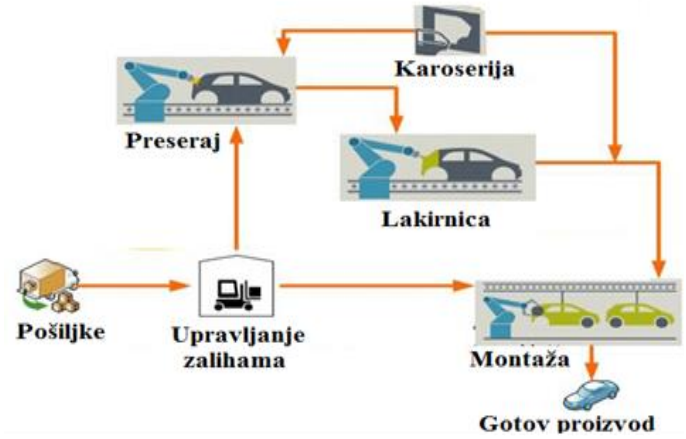

Slika 4. Osnovne faze proizvodnje automobila

\subsection{Lanci snabdevanja automobilske industrije}

Proizvođači automobila (OEM) da bi izbegli proces proizvodnje svih automobiskih sistema i delova unutar svoje fabrike, imaju složeni logistički lanac snabdevanja sastavljen od velikog broja različitih dobavljača, čiji zadatak je proizvodnja sistema, poluproizvoda ili komponenti, koji će biti sastavi deo gotovog automobila (slika 5).

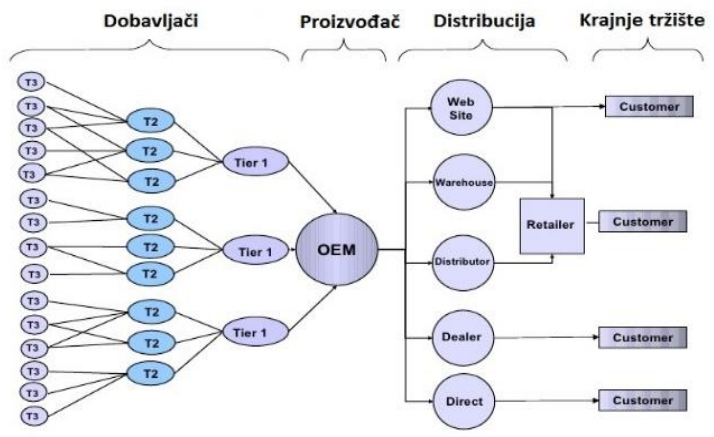

Slika 5. Lanac snabdevanja automobilske industrije [6]

Tier 1 dobavljači su kompanije koje proizvode sisteme i delove kao što su: (elektronski i upravljački sistemi, vazdušni jastuci, sedišta, senzore, gume, pumpe, klima...), koje će se direktno poslati proizvođaču automobila i činiti deo gotovog proizvoda. Tier 2 dobavljači su kompanije koje proizvode poluproizvode koji se šalju dalje ka Tier 1 dobavljaču. Ove kompanije ne posluju direktno sa proizvođačima automobila, već su specijalizovane za izradu delova koji će činiti gotov proizvod Tier 1 dobavljača. Tier 3 dobavljači su specijalizovane kompanije koje proizvode sirovine za potrebe drugih fabrika u lancu snabdevanja, kako bi napravili svoje proizvode, komponente i sisteme.

\section{STUDIJA SLUČAJA-MAPIRANJE LOGISTIČKIH PROCESA}

Studija slučaja je vezana za kompaniju iz kategorije dobavljača prvog reda (Teir 1 ), koja se bavi proizvodnjom kablovskih snopova za automobile. Upravljanje logistikom podrazumeva upravljanje svim logističkim procesima koji se javljaju u preduzeću, sa ciljem ispunjavanja zahteva nastalih od strane kupca [2]. Kako bi se ispunili logistički ciljevi i zadaci u posmatranoj kompaniji, Odsek za logistiku je podeljen na sledeće sektore (slika 6):

- sektor za odnose i saradnju sa kupcem,

- sektor za planiranje proizvodnje,

- sektor za nabavku sirovina,

- sektor za praćenje i analizu zaliha,

- sektor za upravljanje transportom. 


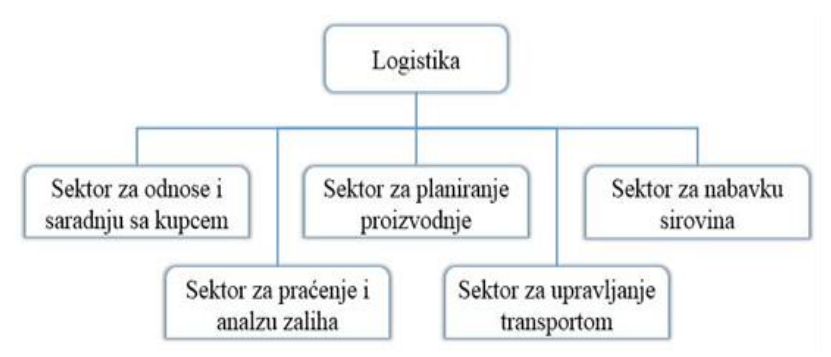

Slika 6. Raspored sektora u Odseku za logistiku

\subsection{Sektor za odnose i saradnju sa kupcem}

Tim za koordinaciju sa kupcem ima osnovni zadatak da uskladi ponudu i potražnju za gotovim proizvodima između proizvodnje i kupca (u ovom slučaju OEM proizvođača automobila). Pored osnovnog zadatka tim za koordinaciju ima zadatak da realizuje, kontroliše i upravlja svim skladišnim, pretovarnim i transportnim procesima koji su neophodni da bi se gotov proizvod isporučio kupcu (OEM).

\subsection{Sektor za planiranje proizvodnje}

$\mathrm{Na}$ osnovu informacija dobijenih od strane kupca (količine i datum isporuke gotovih proizvoda), tim za planiranje proizvodnje može pristupiti procesu planiranja. Prilikom izrade automobilskih kablovskih snopova zastupljena su dva tipa proizvodnje: konvencionalna proizvodnja i KSK proizvodnja. Konvencionalna proizvodnja predstavlja izradu kablovskih snopova na osnovu analize trižišta i odluke proizvođača o tipu vozila koje će se proizvoditi. Ovako dobijen gotov proizvod predstavlja rezultat masovne proizvodnje koja ima za cilj dobijanje određenog broja istih proizvoda. KSK (nem. kundenspezifischer kabelsatz) je skraćenica nemačkog porekla i predstavlja prilagođeni set kablova. KSK proizvodnja se ogleda u pojedinačnoj varijanti svakog proizvoda definisanog na osnovu specifičnog zahteva kupca.

\subsection{Sektor za nabavku sirovina}

Sektor za nabavku sirovina ima zadatak da osigura snabdavanje potrebnim materijalima, kako bi se sprečilo zaustavljanje proizvodnje i ugrožavanje isporuka ka kupcu. Zadaci logistike nabavke orijentisani su na administrativne i fizičke zadatke vezane za tokove materijala, uključuju proveru robe pri prijemu, upravljanje prijemnim skladištem, unutrašnjim transportom, utvrđivanjem količina i vremena isporuke.

\subsection{Sektor za praćenje i analizu zaliha}

U autoindustriji nemoguće je zamisliti lanac snabdevanja bez pojave zaliha nastalih kao rezultat vremenske i prostorne neusklađenosti zahteva između učesnika u lancu snabdevanja. Sektor za praćenje i analizu zaliha svakodnevno analizira tok kretanja materijala unutar preduzeća, kao i nivo zaliha u skladištu. Aktivnosti tima za praćenje i analizu zaliha počinju od trenutka pristizanja sirovine $u$ preuzeće pa sve do trenutka kada gotov proizvod napušta preduzeće.

\subsection{Sektor za upravljanje transportom}

Transport je sa jedne strane ključan za tok kretanja materijala, ali sa druge strane transportni troškovi utiču na cenu gotovog proizvoda. Iz tok razloga sektor za upravljanje transportom ima zadatak da optimizuje transport i obezbedi minimalne troškove transporta. Unutar svakog sektora definisana je mapa logističkih aktivnosti sa ciljem sagledavanja veza i zavisnosti između aktivnosti kao i prava i obaveza svakog zaposlenog u posmatranom preduzeću.

\section{STUDIJA SLUČAJA-ANALIZA LOGISTIČKIH PROCESA}

\subsection{Uvod u praktičan deo rada}

Logistički procesi koji se dešavaju unutar svakog učesnika u lancu snabdevanja povezani su zahvaljujući ERP (eng. enterprise resource planning) sistemima unutar kompanija, dok su veze između kompanija ostvarene putem elektronske razmene podatka (engl. electronic data interchange). Za studiju slučaja analize logističkih procesa korišćen je Excel program, u kome je napravljen model, kao svojevrsna simulacija onoga što ERP sistem radi unutar sektora logistike u posmatranom preduzeću. Ciljevi Excel modela, koja zapravo predstavlja svojevrsnu podršku odlučivanju, su:

- prikazivanje zakonitosti i veza koje postoje unutar sektora logistike,

- proveravanje i podrška radu postojećeg ERP sistema u posmatranom preduzeću,

- omogućavanje razmene podataka između ERP sistema i Excel modela.

Kako bi se u Excel programu prikazali svi logistički procesi unutar preduzeća tj. kupčevi zahtevi sa jedne strane i nabavka sirovina sa druge strane, neophodno je koristiti programski jezik VBA (engl. Visual Basic for Applications). Razvijeni model se zasniva na kreiranju korisničkog interfejsa (engl. UserForm) unutar Excel programa, koristeći VBA programski jezik, sa ciljem mapiranja osnovnih logističkih procesa u posmatranom preduzeću, koji će omogućiti lakše dalje praćenje i analizu podataka u tim procesima. Radi bolje preglednosti logističkih aktivnosti, korisnički interfejs je podeljen na sledeće podsisteme:

- Interfejs dijagrama aktivnosti,

- Interfejs koordinacije sa kupcem (OEM),

- Interfejs pregled zahteva od kupca (OEM),

- Interfejs planiranje proizvodnje,

- Interfejs BOM lista,

- Interfejs nabavke materijala,

- Interfejs porudžbenica,

- Interfejs dijagrama aktivnosti.

Detaljno prikazivanje rada celog modela je nemoguće prikazati kroz par stranica iz tog razloga će se prikazati samo osnove interfejsa Koordinacija sa kupcem (OEM) i interfejs Nabavke materijala.

\subsection{Interfejs Koordinacija sa kupcem (OEM)}

Kupac nakon što definiše svoje kratkoročne i dugoročne planove, prosleđuje svoje zahteve ka kompaniji za prozivodnju kablova, gde su ključne tri vrste informacija: definisanje tipa gotovog proizvoda, zahtevana količina, datum isporuke gotovih proizvoda kupcu. Da bi se izvršilo sagledavanje zahteva od kupca, podaci se iz ERP sistema posmatranog preduzeća prebacuju u razvijeni model u Excelu (slika 7). 


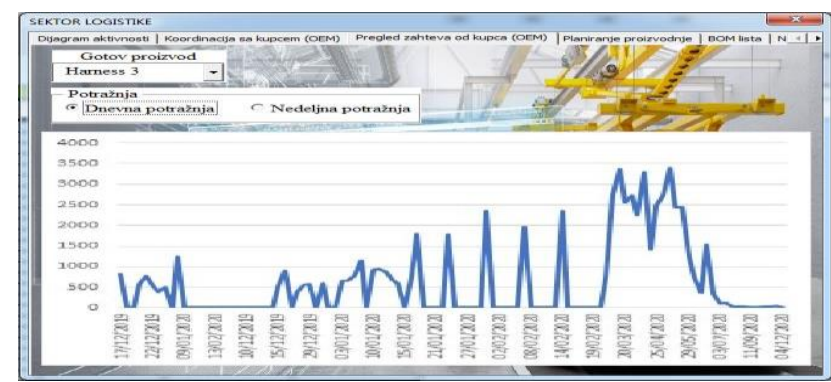

Slika 7. Dnevni prikaz potražnje od kupca za gotovim proizvodom

Nakon što tim za koordinaciju izvrši alanizu zahteva od kupca pristupa se izradi plana isporuke gotovih proizvoda, plan proizvodnje i plan nabavke materijala. Svaki od navedenih planova je detaljno prikazan u master radu.

\subsection{Interfejs Nabavka materijala}

Plan nabavke mora biti definisan tako da svi materijali stignu na vreme u kompaniju, kako bi se sprečilo zaustavljanje proizvodnje usled nedostatka materijala. Plan nabavke uzima u obzir sledeće uslove: vreme koje je potrebno od trenutka kada se poruči materijal pa do njegove isporuke (engl. lead time), vreme transporta od dobavljača do posmatrane kompanije (engl. transport lead time), broj isporuka $\mathrm{u}$ toku nedelje, datum slanja pošiljke od dobavljača, datum pristizanja pošiljke $u$ posmatranu kompaniju,minimalna količina robe koja se može poručiti (engl.minimum quantity order). Što je veći broj uslova koji moraju biti ispunjeni prilikom pokretanja MRP (engl. material requirements planning) odnosno definisanja plana nabavke (slika 8), to su izlazni rezultati tačniji i oslikavaju realno stanje u lancu snabdevanja.

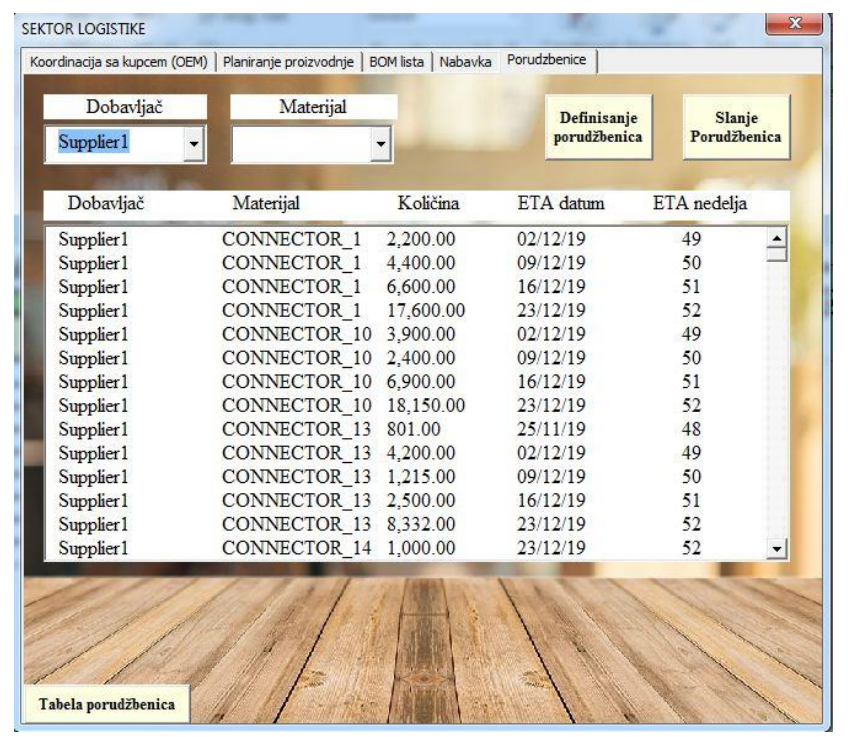

Slika 8. Tabelarni prikaz plana nabavke materijala od jednog dobavljača

\section{ZAKLJUČAK}

Lanac snadbevanja u automobilskoj industriji predstavlja jedan od najsloženijih i najkompleksnijih sistema današnjice. Zbog svoje složenosti, nije moguće sagledati detaljno ceo lanac snadbevanja kroz jedan rad, pa je fokus ovog rada na logističkim procesima koji vladaju unutar posmatranog preduzeća za proizvodnju kablovskih snopova. Tema je izrazito aktuelna pošto je poslednjih godina na teritoriji Srbije otvoren veliki broj preduzeća, kao što su: Continental, Magna, Hutchinson, Aptiv, Lear, Bosch, Yura, Leoni, PKC group, koji predstavljaju učesnike u lancima snadbevanja automobilske industrije.

Konkretan doprinos ovog rada prikazan je kroz dva poglavlja vezana za studiju slučaja mapiranja logističkih procesa i predloženog sistema analize logističkih procesa posmatrane kompanije. Studija slučaja vezana za mapiranje logističkh procesa daje prikaz svih aktivnosti i veza unutar sektora logistike posmatranog preduzeća. Studija slučaja vezana za razvoj sistema, odnosno modela analize logističkih procesa, ima za cilj da prikaže način funkcionisanja logističkih procesa podržan od strane ERP (engl. Enterprise resource planning) sistema, unutar sektora logistike posmatranog preduzeća.

U radu je razvijen odgovarajući model u Excelu koji je u direktnoj vezi sa ERP sistemom, i koji pokazuje zakonitosti i veze koje postoje unutar sektora logistike, prikazivanje mapa logističkih aktivnosti, definisanje plana proizvodnje, definisanje plana nabavke i proveravanje ispravnosti rada postojećeg ERP sistema u posmatranom preduzeću. Excel model sadrži korisnički interfejs koji omogućava lako sagledavanje svih procesa i aktivnosti unutar sektora logistike. Korisnički interfejs je napravljen primenom programskog jeziku VBA (engl. Visual Basic for Applications) koji omogućava automatsko izvršavanje zadatih komandi unutar modela.

\section{LITERATURA}

[1] Nikoličić S.,Stojanović Đ., Maslarić M., Osnove logističke: principi, sistemi i procesi, Univerzitet u Novom Sadu, Fakultet tehničkih nauka, 2016.

[2] Kamthunzi E., Analysis of logistic process, HAMK University of appliled sciences, 2014.

[3] www.ford.com (pristupljeno u martu 2020.)

[4] www.oica.net (pristupljeno u martu 2020.)

[5] www.ras.gov.rs (pristupljeno u martu 2020.)

[6] https://blogs.sap.com/2016/04/22/businessprocessmanagement-how-it-can-change-the-face-ofsmall-businesses/ (pristupljeno u martu 2020.)

\section{Kratka biografija:}

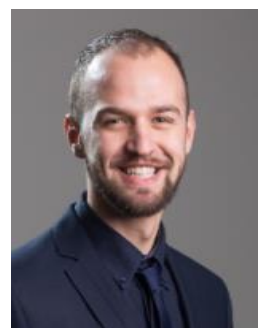

Vladimir Stijović rođen je u Peći 1994. god. Nakon završene srednje saobraćajne škole u Čačku svoje obrazovanje nastavlja na Fakultetu tahničkih nauka u Novom Sadu, gde je 2016. godine stekao zvanje Diplomiranog inženjera saobraćaja.

Kontakt: vladimirstijovic94@gmail.com 